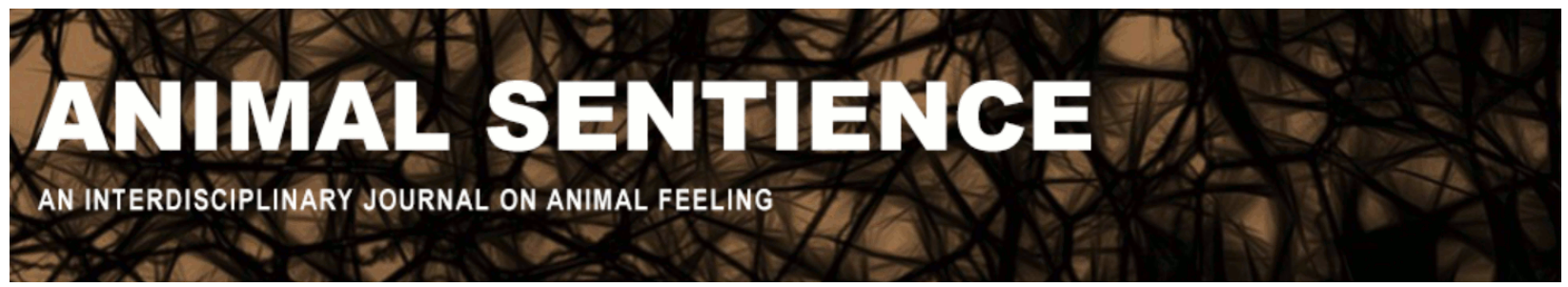

Harris, Lasana T. (2017) Do we understand what it means for dogs to experience emotion?. Animal Sentience 14(8)

DOI: $10.51291 / 2377-7478.1254$

Date of submission: 2017-11-14

Date of acceptance: 2017-11-19

(c) $\underset{\mathrm{EY}}{\mathrm{C}}$

This article has appeared in the journal Animal

Sentience, a peer-reviewed journal on animal

cognition and feeling. It has been made open access,

free for all, by WellBeing International and deposited

in the WBI Studies Repository. For more information,

please contact

wbisr-info@wellbeingintl.org.

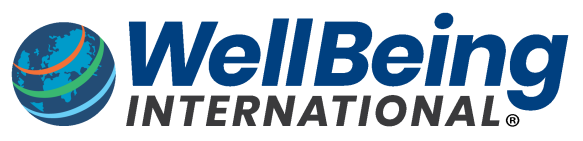

SOLUTIONS FOR PEOPLE, ANIMALS AND ENVIRONMENT 


\title{
Do we understand what it means for dogs to experience emotion?
}

\author{
Commentary on Kujala on Canine Emotions
}

\author{
Lasana T. Harris \\ Department of Experimental Psychology \\ University College London
}

\begin{abstract}
Psychologists who study humans struggle to agree on a definition of emotion, falling primarily into two camps. Though recent neuroscience advances are beginning to settle this ancient debate, it cannot solve the private-language problem at the heart of inferences about social cognition. This suggests that when we consider the emotional experiences of other species like canines, biological and physiological homologs do not provide enough evidence of emotional experiences similar to those of humans. Secondary complex emotional experiences are even more difficult to attribute to non-humans since such experiences rely, by definition, on social cognition. Given the contextual differences between human-human and canine-human interactions, the communicative function of emotions may also differ in canines.
\end{abstract}
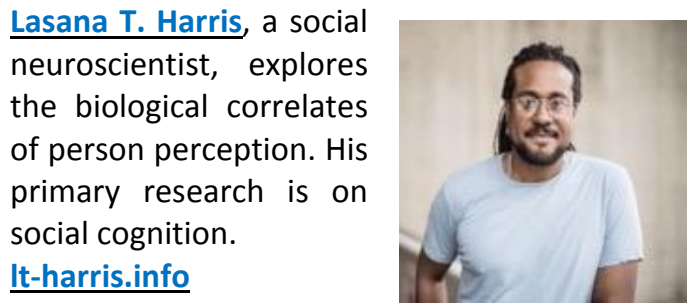

Psychologists struggle to agree on a definition of emotion (Fox, Lapate, Shackman, \& Davidson, in press). This struggle harkens back to the very earliest psychologists, who differed in their explanation of the unfolding of an emotional sequence. Imagine being in the forest and encountering a bear. The emotion associated with such an experience might be fear. But how does fear in such an instance occur? One school of thought supported by Darwin's (1872) theory of basic emotions is that people experience a fear response to the stimulus (the bear), which triggers appropriate behaviour, such as running away screaming (Ekman \& Friesen, 1971). The other school of thought, associated with the James \& Lange (1922) theory, suggests that people first display a behavioural response to the stimulus (run away from the bear), then interpret their behaviour as consistent with the emotion fear, inferring that they must indeed be afraid (Lang, 1994). These two competing accounts of emotions battled for over a century, with scientific evidence mounting on both sides.

More recent neuroscience evidence, however, is beginning to settle the debate. Two meta-analyses of the brain imaging literature published months apart came to a very different conclusion about the brain correlates of basic emotions (Phan, Wager, Taylor, Liberzon, 2002; Murphy, Nimmo-Smith, \& Lawrence, 2003). This suggested that no brain region or network was specialised for happiness, sadness, anger, fear, disgust, or surprise. This is verified by a body of 
literature suggesting that the brain has a generalised emotional response, interpreted by the person based on their prior history, personality, social, and physical context, and represented in language (Barrett, Lindquist, \& Gendron, 2007; Lindquist, Wager, Kober, Bliss-Moreau, \& Barrett, 2012). Other supporting evidence comes from studies of people with brain lesions; an amygdala lesion preserves physiological fear responses, yet such people report no accompanying experience of fear (Anderson \& Phelps, 2001). One such person might report knowing what fear is, and that they should be afraid of the fear-conditioned stimulus, yet not report feeling fear itself. Even Darwin's proposition about the universality of basic emotional facial expressions has come under recent review by cultural anthropologists and psychologists who failed to find a correspondence between fearful faces and attributions of fear to the faces (participants attributed anger instead) in a hunter-gatherer tribe in Papua New Guinea similar to the one Darwin visited (Crivelli, Jarillo, Russell, \& Fernández-Dols, 2016; Crivelli, Russell, Jarillo, \& Fernández-Dols, 2016; Crivelli, Russell, Jarillo, \& Fernández-Dols, 2017). Yes, even the father of evolutionary theory has been touched by the replication crisis in psychology.

What does this mean, then, for our understanding of the emotional experience of other species such as dogs (Kujala, 2017)? First, biological and physiological homologues necessary for emotional responding, including 'limbic' brain regions, hormonal changes, and other physiological displays such as vocalisations, pupil dilations, sweating, and freezing behaviour, may not be enough to support the claim that any other species experiences emotion. Since the hallmark of human emotional experience is an interpretation of such biological and physiological signals marked by language, as well as behavioural displays, to attribute the experience of emotion to another species requires identifying and demonstrating this interpretive ability. This remains a difficult task even in humans because interpretation suffers from a private language problem (Wittgenstein, 1953); it lives in the mind of a person who is the only one with access to it. Moreover, if language is necessary to translate emotional qualia into measurable reality, then obviously the lack of language in other species only adds to this measurement problem. Hence evidence for the interpretation of emotional physiology cannot come primarily from self-report, which may itself often change physiological responses to stimuli, presumably changing the emotional experience.

Second, the discussion thus far has focussed on basic emotion, not secondary emotions or sentiments. A failure to attribute such emotions to other people is a hallmark of dehumanising; people attribute less secondary positive and negative emotions to outgroup members compared to ingroup members (Leyens et al., 2001). Given that the experience of secondary emotions is perceived as unique to humans, this suggests that more complex emotional responses such as regret, pity, schadenfreude, and nostalgia may not be attributable to non-human animals by human beings. There is much less debate, however, about the role of social cognitive processing in producing secondary emotions; social cognition is viewed as necessary to experiencing and attributing secondary emotions. Is it hence possible for such emotions to exist in other species? Or rather: What degree of social cognitive complexity is necessary to support secondary emotions? Such questions remained unanswered because they again rely on language and are plagued by the private language problem - but also because our understanding of social cognition, and of the brain, across disciplines, is not yet advanced enough.

Finally, one must consider whether the suite of human emotional experience applies directly to other species. Emotions serve to communicate information about a person's internal 
state within social contexts (Harris, 2017); are the same lines of communication necessary in the social context of other species? Indeed, in considering canines, the communicating dyad is often human-dog rather than dog-dog: Would an emotional system have evolved to facilitate communications within this dyad, or just among other canines? To answer this question, we must know whether all social contexts require communicating the same things about the internal states of their actors. Human-dog contexts are certainly quite different from dog-dog contexts, so any emotional system has to be able to fulfil communicative functions in both contexts. Whether such a sophisticated system exists remains unknown.

\section{References}

Anderson, A. K., \& Phelps, E. A. (2001). Lesions of the human amygdala impair enhanced perception of emotionally salient events. Nature, 411(6835), 305-309.

Barrett, L. F., Lindquist, K. A., \& Gendron, M. (2007). Language as context for the perception of emotion. Trends in Cognitive Sciences, 11(8), 327-332.

Crivelli, C., Jarillo, S., Russell, J. A., \& Fernández-Dols, J. M. (2016). Reading emotions from faces in two indigenous societies. Journal of Experimental Psychology: General, 145(7), 830.

Crivelli, C., Russell, J. A., Jarillo, S., \& Fernández-Dols, J. M. (2016). The fear gasping face as a threat display in a Melanesian society. Proceedings of the National Academy of Sciences, 201611622.

Crivelli, C., Russell, J. A., Jarillo, S., \& Fernández-Dols, J. M. (2017). Recognizing spontaneous facial expressions of emotion in a small-scale society of Papua New Guinea. Emotion, 17(2), 337.

Darwin, C. (1872). The Expression of Emotion in Animals and Man. London: John Murray.

Ekman, P., \& Friesen, W. V. (1971). Constants across cultures in the face and emotion. Journal of Personality and Social Psychology, 17(2), 124.

Fox, A. S., Lapate, R. C., Shackman, A. J., \& Davidson, R. J. (Eds.). (in press). The Nature of Emotion: Fundamental Questions (2nd edition). New York: Oxford University Press.

Harris, L. T. (2017). Invisible Mind: Flexible Social Cognition and Dehumanisation. Cambridge, MA: MIT Press.

James, W., \& Lange, C. (1922). The Emotions (Volume 1). Baltimore: Williams \& Wilkins Co.

Kujala, M. V. (2017). Canine emotions as seen through human social cognition. Animal Sentience 14(1).

Lang, P. J. (1994). The varieties of emotional experience: A meditation on James-Lange theory. Psychological Review, 101(2), 211-221.

Leyens, J. P., Rodriguez-Perez, A., Rodriguez-Torres, R., Gaunt, R., Paladino, M. P., Vaes, J., \& Demoulin, S. (2001). Psychological essentialism and the differential attribution of uniquely human emotions to ingroups and outgroups. European Journal of Social Psychology, 31(4), 395-411.

Lindquist, K. A., Wager, T. D., Kober, H., Bliss-Moreau, E., \& Barrett, L. F. (2012). The brain basis of emotion: A meta-analytic review. Behavioral and Brain Sciences, 35(3), 121-143.

Murphy, F. C., Nimmo-Smith, I. A. N., \& Lawrence, A. D. (2003). Functional neuroanatomy of emotions: A meta-analysis. Cognitive, Affective, \& Behavioral Neuroscience, 3(3), 207-233.

Phan, K. L., Wager, T., Taylor, S. F., \& Liberzon, I. (2002). Functional neuroanatomy of emotion: A metaanalysis of emotion activation studies in PET and fMRI. Neuroimage, 16(2), 331-348.

Wittgenstein, L. (1953). Philosophical Investigations, translated by G. E. M. Anscombe. Oxford: Blackwell, 3rd edition, 1967. 